\title{
THE ARBOREAL MICROSNAIL PUPISOMA DIOSCORICOLA (C. B. ADAMS, 1845) FROM WEST BENGAL, INDIA: MORPHOLOGY, PLANT PREFERENCES AND DISTRIBUTION
}

\author{
Himangshu Barman ${ }^{a, b}$, Pranesh Paul ${ }^{a}$, Gautam Aditya ${ }^{a *}$

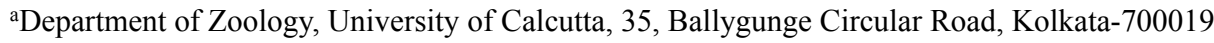 \\ bDepartment of Zoology, Ramnagar College, Depal, Purba Medinipur, 721453, West Bengal, India \\ *Corresponding author. Email: gautamaditya2001@gmail.com
}

Article history

Received: 24 September 2021; accepted 25 November 2021

\section{Keywords:}

Distribution; habitat utilization; host plant; Jacobs' selectivity; morphometry

\begin{abstract}
The microsnails (Mollusca: Gastropoda), featured by miniscule size (adult shell size $<5 \mathrm{~mm}$ ), are little explored among the Indian terrestrial malacofauna. In the present study, the morphological features, host plant preference and predicted distribution of the arboreal microsnail Pupisoma dioscoricola (C. B. Adams, 1845) (Gastropoda: Valloniidae) are characterized from West Bengal, India. The shell features were highly correlated and showed a positive correlation with body weight. The apical angle of the shell of $P$. dioscoricola was negatively correlated with shell height and body weight and revealed a typical value, indicative of the arboreal adaptations. The toothless pupa snail $P$. dioscoricola exhibited a greater preference for the mango tree over China rose, Bengal quince, Indian mahogany and coconut as a host plant. The results of the species distribution modelling suggested that cultivated or managed vegetation and annual precipitation might be the most influential factors for its distribution. Although the present study is a pioneer effort to describe the plant preferences and the morphological features of the microsnail $P$. dioscoricola, further studies should be carried out to decipher the functional roles and conservation management of such an apparently cryptic organism.
\end{abstract}

\section{INTRODUCTION}

Microsnails constitute a unique group of land snails (Mollusca: Gastropoda) characterized by the minuscule size (up to $5 \mathrm{~mm}$ in length) in the adult stage (Panha and Burch 2005). Different species of microsnails have been encountered from a wide range of habitats, including trees, shrubs, and even in the subterranean environments in China, Croatia, Japan, Malaysia, Thailand and the USA (Pilsbry 1920-21; Hausdorf 2007; Kawakami et al. 2008; Tongkerd et al. 2013; Weigand 2013; Páll-Gergely et al. 2015; Vermeulen et al. 2015; Salvador et al. 2017).The size, morphological variation and habitat utilization pattern are the emergent features of research on microsnails in different regions (Hausdorf 2007; Kawakami et al. 2008; Tongkerd et al. 2013; Páll-Gergely et al. 2015; Vermeulen et al. 2015). Owing to the body size, representatives of the genera Acmella, Gastrocopta, Georissa, Pupisoma and Rahula constitute the microsnails of India (Pilsbry 1920-21; Mitra et al. 2005; Raheem et al. 2014; Das and Aravind 2021). Apart from the taxonomic details (Rao 1925; Mitra et al. 2005), information on the biology and ecology of these microsnails is yet to be explored from India. However, considerable information on the land snail diversity is available, mainly from the Western Ghats (Aravind et al. 2005, 2008; Sen et al. 2012; Raheem et al. 2014; Madhyastha and Mumbrekar 2016) that substantiate the functional roles attributable to the land snails. Despite the ecological significance of the land snails, several factors have been identified that contribute to their loss from the terrestrial ecosystem (Aravind et al. 2008). Thus, exploration of the land snails, particularly the microsnails, is required to conserve and sustain their functional roles.

In course of the land snail survey in different regions of West Bengal, India, the microsnail Pupisoma dioscoricola (C. B. Adams, 1845) (Gastropoda: Valloniidae) was observed in varying numbers in different plants. The records from Brazil (Cunha et al. 2015; Salvador et al. 2017), China (Páll-Gergely et al. 2015), Singapore (Sow-Yan and Lup 2020) and the USA (Vermeulen and Raven 1988; Hausdorf 2007) justify the worldwide presence of $P$. dioscoricola. Although known to be a part of the malacofauna of West Bengal (Pilsbry 1920-21), information on the morphology and ecology of these microsnails is yet to be deciphered in greater detail. Thus, an attempt to document the host plant preferences and the morphological details of $P$. dioscoricola was carried out to understand the regional scale distribution pattern with respect to the possible influences of the plant species from West Bengal, India. The morphological features of $P$. dioscoricola were also evaluated for comparison with the species occurring elsewhere (Hausdorf 2007). 
The distribution of land microsnails largely depends on environmental factors, such as temperature, humidity and precipitation, along with the vegetation structure and anthropogenic disturbances (Labaune and Magnin 2001; Aravind et al. 2008; Douglas et al. 2013). Depending on the observation of $P$. dioscoricola in different study areas, species distribution modelling was carried out to predict its suitable habitat ranges in West Bengal, India, using the Maxent software, which can predict distributions based on presence-only data (Phillips 2017). For instance, Maxent modelling was used to predict the potential distribution range, risk of invasion and effect of climate change on several land snail species (Vogler et al. 2013; Beltramino et al. 2015; Hausdorf et al. 2021). The results of the present study will be a valuable contribution to the knowledge of minuscule-sized land snails in the Indian context.

\section{MATERIALS AND METHODS}

\section{Study sites and sampling}

As a part of the assessment of land snail diversity, regular surveys during the monsoon periods (July to September) of 2017 and 2021were conducted in different districts of West Bengal, India. The study area, West Bengal, is situated in the eastern region of India and consists of diverse geographic features, including Darjeeling Himalayan hill regions, foothills and Dooars in the northern extreme, western plateau and high lands, Sundarbans mangrove forest and coastal area in the extreme south and plain lands in between (Figure 1). The surveys were carried out during the early morning and late evening, including search of snails in the randomly selected multiple quadrats of $10 * 10$ meters of bushes, gardens and shrubbery near the human settlements $(n=42)$ (Sturm et al. 2006; Fontaine et al. 2007). In a particular sampling quadrat, if a plant was found positive for the presence of the snail $P$. dioscoricola, rigorous visual search was continued through the entire bark, stem and the leaves as the microhabitat spaces up to reachable height. Although the sampling efforts varied in the surveyed quadrats owing to the differences in the number of plants per quadrat, at least 30 minutes time was spend for the search of $P$. dioscoricola in the plants, which remained the same for all the positive quadrats. A repeat scrutiny of the selected plants was also carried out at different times during the survey to ascertain the presence of $P$. dioscoricola. During the surveys, the microsnail was encountered in 10 locations (a total of 16 quadrats) belonging to 8 districts of West Bengal, India (Figure 1). In case of the positive plants, the relative abundance of $P$. dioscoricola in a plant was noted along with the name of the plant. Following this, the snails were collected from plants by the hand-picking method

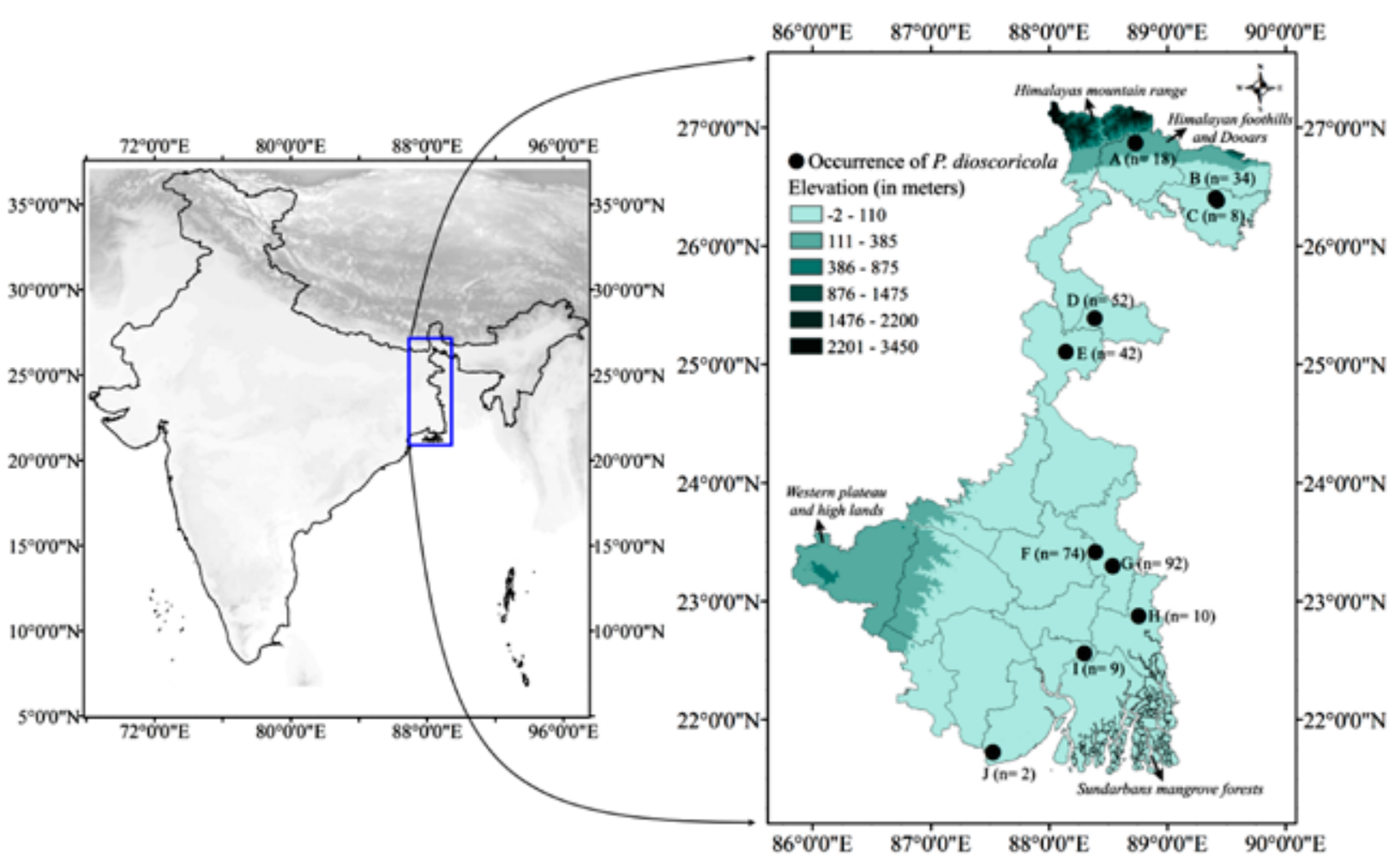

Figure 1. Map of the study area. Among different randomly selected survey areas of West Bengal, India, P. dioscoricola was encountered at (A) Malbazar, Jalpaiguri district, (B and C) Basantapur and Konamalli, Cooch Behar district, (D) Buniadpur, Dakhshin Dinajpur district, (E) Gunsharkol, Malda district, (F and G) Swarupganj and Purba Badkulla, Nadia district, (H) Gobardanga, North 24 Parganas district, (I) Acharya Jagadish Chandra Bose Indian Botanic Garden, Howrah district, and (J) Hamirpur, Purba Medinipur district ['n' indicates the number of $P$. dioscoricola encountered in the given survey area]. 
with a fine paintbrush and brought to the laboratory with water-dense tissue paper to maintain higher humidity (Raut and Ghose 1984; Barman and Aditya 2021). In all instances, extreme caution was taken for the picking and subsequent transfer of $P$. dioscoricola, particularly, when these were available in the barks of the trees with considerable camouflage against the background of the bark. The collected $P$. dioscoricola were brought to the laboratory for the assessment of bodyweight, shell height and other parameters to characterize the morphology (Hausdorf 2007; Barman and Aditya 2021).

\section{Morphometric analysis}

The shells of the snails were photographed using a microscope digital camera (DGI 510, Dewinter, India) fitted with a binocular microscope (SZ2-ILST, Olympus, Japan) and were used for identification and presentation. Selected shells were dried, placed in carbon tape and further coated with a platinum layer for obtaining the image through scanning electron microscopy (EVO 18 special edition, Zeiss, Germany). Based on the pupiform shell shape, colour, fine incised spiral striae texture, number of whorls and aperture shape, collected arboreal microsnails were identified as the toothless pupa snail, P. dioscoricola (Figure 2) (Pilsbry 1920-21; Hausdorf 2007).Using a binocular light microscope fitted with an ocular micrometre (Erma, Japan), the morphological features of the living $P$. dioscoricola were measured to the nearest $0.1 \mathrm{~mm}$. Among the morphological features of $P$. dioscoricola, shell height ( $\mathrm{SH}$, in $\mathrm{mm}$ ), shell width ( $\mathrm{SW}$, in $\mathrm{mm}$ ), aperture length ( $\mathrm{AL}$, in $\mathrm{mm}$ ), aperture width (AW, in $\mathrm{mm}$ ) and spire ratio (SR- SH/SW) were measured. In addition, the ratio of $\mathrm{SW} / \mathrm{SH}, \mathrm{SH} / \mathrm{AL}$ and $\mathrm{AW} / \mathrm{AL}$ were deduced equivalent to the measures of morphology of $P$. dioscoricola observed elsewhere (Hausdorf 2007). The apical angle $\left(\mathrm{AA}^{\circ}\right)$ of the shell was also calculated using the formula $A A=2 * \tan [(0.5 X$ $S W) /(S H)]$ (Preston and Roberts 2007). The body weight (BW) of living $P$. dioscoricola was measured using a fine pan balance (Afcoset, India) to the nearest $0.1 \mathrm{mg}$. Using regression equations and correlation coefficients (Zar 1999), the relationship among the morphological variables of live $P$. dioscoricola $(\mathrm{n}=110)$ was deduced using XLSTAT software version 9.0 (Addinsoft 2010). The coefficient of determination values (Zar 1999) were considered for selection of the best fit regression equations between any two morphological variables.

\section{Plant preference analysis}

Host plant preference was assessed using Jacobs' selectivity index $\left(D_{i a}\right)$ (Jacobs 1974), which was calculated based on 341 occurrences using the equation:

$$
D_{i a}=\frac{\left(r_{i}-p_{a}\right)}{\left(r_{i}+p_{a}-2 r_{i} p_{a}\right)}
$$

(where $D_{i a}$ is the selectivity index of snail species ' $i$ ' for plant ' $a$ ', ' $r_{i}$ ' is the ratio of plant type ' $a$ ' used to all other plant types used by that species, and ' $p_{a}$ ' is the ratio of plant type ' $a$ ' to all other plants available for the individual to use within the local area). Among the entire surveyed sites of West Bengal, India, the data of the quadrats positive for the snail $P$. dioscoricola $(\mathrm{n}=$ 16) were considered to perform the plant preference analysis.

\section{Species distribution modelling}

During the sampling, the latitudes and longitudes of the study area were obtained from Google Maps for the

(a)
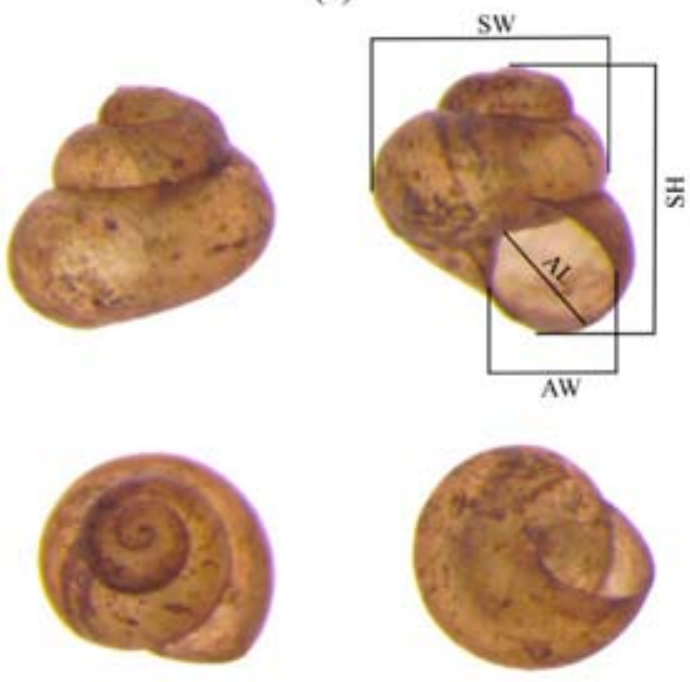

$0.5 \mathrm{~mm}$ (b)
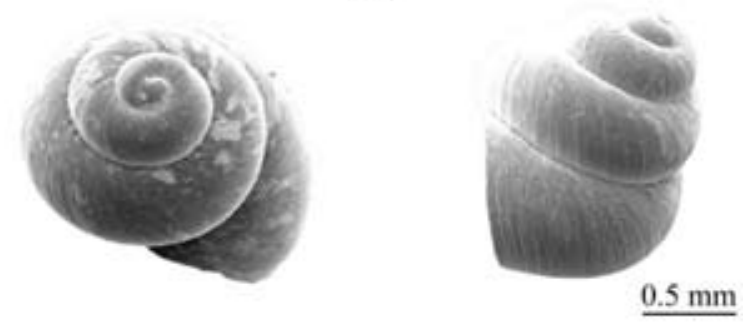

Figure 2. (a) Photographs and (b) SEM images of $P$. dioscoricola shells indicating different morphological variables ( $\mathrm{SH}$ - shell height, SW - shell width, AL - aperture length, and AW - aperture width. 
Table 1. (a) Different variables of shell morphological variables with range and mean $\pm \mathrm{SE}$ and (b) the coefficient of correlation among the various morphological variables of live $P$. dioscoricola $(\mathrm{n}=110)[\mathrm{SH}-$ shell height in mm, BW - body weight in $\mathrm{mg}, \mathrm{SW}$ - shell width in $\mathrm{mm}, \mathrm{AL}$ - aperture length in $\mathrm{mm}, \mathrm{AW}$ - aperture width in mm, AA - apical angle, and $\mathrm{SR}-$ spire ratio]. The values in bold indicate significance at $p<0.001$ level.

(a)

\begin{tabular}{|c|c|c|c|c|}
\hline SH $(\mathrm{mm})$ & SW $(\mathrm{mm})$ & AL $(\mathrm{mm})$ & AW $(\mathrm{mm})$ & BW $(\mathrm{mg})$ \\
\hline $0.64-2.1$ & $0.63-1.88$ & $0.4-1.3$ & $0.26-1.09$ & $0.12-2.62$ \\
$1.53 \pm 0.02$ & $1.5 \pm 0.02$ & $0.89 \pm 0.01$ & $0.76 \pm 0.01$ & $1.28 \pm 0.04$ \\
\hline $\mathrm{AA}^{\circ}$ & $\mathrm{SR}$ & $\mathrm{SW} / \mathrm{SH}$ & $\mathrm{SH} / \mathrm{AW}$ & $\mathrm{AL} / \mathrm{AW}$ \\
\hline $0.86-1.85$ & $0.67-1.24$ & $0.81-1.49$ & $1.15-4.32$ & $0.68-1.71$ \\
$1.08 \pm 0.02$ & $1.02 \pm 0.01$ & $0.99 \pm 0.01$ & $2.08 \pm 0.04$ & $1.2 \pm 0.02$ \\
\hline
\end{tabular}

(b)

\begin{tabular}{|c|c|c|c|c|c|c|c|c|c|}
\hline Variables & $\mathrm{SH}(\mathrm{mm})$ & $\mathrm{SW}(\mathrm{mm})$ & $\mathrm{AL}(\mathrm{mm})$ & AW (mm) & BW (mg) & $\mathrm{AA}^{\circ}$ & SR & SW/SH & SH/AW \\
\hline $\mathrm{SW}(\mathrm{mm})$ & 0.753 & & & & & & & & \\
\hline $\mathrm{AL}(\mathrm{mm})$ & 0.655 & 0.613 & & & & & & & \\
\hline $\mathrm{AW}(\mathrm{mm})$ & 0.397 & 0.626 & 0.550 & & & & & & \\
\hline BW (mg) & 0.824 & 0.680 & 0.608 & 0.397 & & & & & \\
\hline $\mathrm{AA}^{\circ}$ & -0.545 & 0.112 & -0.240 & 0.185 & -0.329 & & & & \\
\hline SR & 0.540 & -0.137 & 0.210 & -0.198 & 0.367 & -0.967 & & & \\
\hline SW/SH & -0.549 & 0.118 & -0.235 & 0.189 & -0.341 & 0.998 & -0.982 & & \\
\hline SH/AW & 0.317 & -0.066 & -0.126 & -0.695 & 0.194 & -0.556 & 0.574 & -0.565 & \\
\hline AL/AW & 0.122 & -0.169 & 0.236 & -0.660 & 0.090 & -0.418 & 0.411 & -0.420 & 0.742 \\
\hline
\end{tabular}

species distribution modelling study. The bioclimatic (Fick and Hijmans 2017) and land cover (Tuanmu and Jetz 2014) variables were downloaded from World Clim global climate (www.worldclim.org) and consensus land cover (www.earthenv.org) database in GeoTiff (.tif) format ( $\sim 1 \mathrm{~km}^{2}$ resolution). Additionally, the .tif files were reduced to the extent of our study area using a shape file of West Bengal, India, and converted to ASCII raster format using ArcGIS software version 10.8 (ESRI 2019). To model and predict the distribution of $P$. dioscoricola in West Bengal, India, selected bioclimatic and land cover (Table $2 \mathrm{a}$ ) and $P$. dioscoricola occurrence data were used in Maxent software version 3.4.4 (Phillips 2017). The modelling was based on the maximum entropy theory, which evaluates the maximised probability distribution by considering a set of constraints in the correspondence of environmental data associated with the species occurrence points (Phillips et al. 2006). The default parameter settings were used to run the model, which used 10 presence records for training and 9999 background points to determine the distribution model. Additionally, the percent variable contribution and jackknife procedure were applied to calculate the contribution of each environmental and land cover variable to the model. The output returned a continuous map of presence probability ( 0 to 1$)$. The model provided the Area Under the Curve (AUC), which measures the ability of the model to distinguish presence or background data. The values of $A U C<0.5$ are worse than random, $0.5-0.7$ indicate poor performance, $0.7-0.9$ indicate moderate performance, and $>0.9$ signify high model performance (Peterson et al. 2011).

\section{RESULTS}

\section{Morphometry}

The morphological features and body weight of $P$. dioscoricola and the corresponding correlation coefficients are shown in Table 1. Almost all the paired morphological variables remained significant for the values of the Pearson's product moment correlation coefficient values. Apparently, the shell height was a better predictor of the variation in the morphological features owing to its high and significant correlation with variables including body weight. Among the morphological variables, power regression equations (Figure 3) (shell width $(\mathrm{y})=1.115^{*}$ shell height $(\mathrm{x})^{0.694}$; body weight $(\mathrm{y})=0.486^{*}$ shell height $(\mathrm{x})^{2.114}$; aperture length $(y)=0.654 *$ shell height $(x)^{0.694}$, and aperture width $(y)=0.585^{*}$ shell height $\left.(x)^{0.579}\right)$ were the best fit, revealed through the values of the coefficient of determination $\left(\mathrm{R}^{2}\right)$. The apical angle was a reducing function with the shell height and the body weight of $P$. dioscoricola reflecting the conical pattern of the shell.

\section{Plant preference}

The microsnail $P$. dioscoricola was encountered in 16 quadrats, ranged between 2-71 individuals per quadrat $(21.31 \pm 5.30 \mathrm{SE})$. Among the total of 21 plant species in the surveyed bushes and gardens (Figure 4a), five host plants, namely Mangifera indica (mango), Hibiscus rosa-sinensis (China rose), Aegle marmelos (Bengal quince), Chukrasia tabularis (Indian mahogany) and Cocos nucifera (coconut), were identified to host $P$. dioscoricola $(\mathrm{n}=2-52)$ (Figure 4b). The Jacobs' selectivity 
Table 2. (a) The list of variables used to predict the distribution of P. dioscoricola in West Bengal, India, and (b) relative contributions and permutation importance of the variables to the Maxent distribution model in this study.

(a)

\begin{tabular}{|c|c|c|}
\hline & Variables & Source \\
\hline \multirow{5}{*}{ 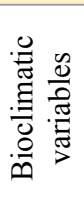 } & Annual mean temperature & \multirow{5}{*}{$\begin{array}{l}\text { Worldclim } \\
\text { (Fick and Hijmans 2017) } \\
\text { www.worldclim.org }\end{array}$} \\
\hline & Mean temp of wettest quarter & \\
\hline & Annual precipitation & \\
\hline & Mean diurnal range & \\
\hline & Temperature seasonality & \\
\hline \multirow{9}{*}{ 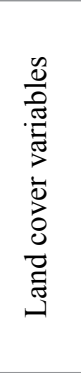 } & Cultivated and managed vegetation & \multirow{9}{*}{$\begin{array}{l}\text { Consensus land cover } \\
\text { (Tuanmu and Jetz 2014) } \\
\text { www.earthenv.org }\end{array}$} \\
\hline & Deciduous broadleaf trees & \\
\hline & Herbaceous vegetation & \\
\hline & Mixed/ other trees & \\
\hline & Open water & \\
\hline & Regularly flooded vegetation & \\
\hline & Shrubs & \\
\hline & Urban/ built-up & \\
\hline & Barren & \\
\hline
\end{tabular}

(b)

\begin{tabular}{|l|c|c|}
\hline \multicolumn{1}{|c|}{ Variables } & $\begin{array}{c}\text { Percent } \\
\text { contribution }\end{array}$ & $\begin{array}{c}\text { Permutation } \\
\text { importance }\end{array}$ \\
\hline $\begin{array}{l}\text { Regularly flooded } \\
\text { vegetation }\end{array}$ & 45.6 & 3.1 \\
\hline $\begin{array}{l}\text { Annual } \\
\text { precipitation }\end{array}$ & 19.6 & 45.5 \\
\hline $\begin{array}{l}\text { Deciduous } \\
\text { broadleaf trees }\end{array}$ & 18.9 & 2.9 \\
\hline Open water & 7.6 & 0.5 \\
\hline $\begin{array}{l}\text { Cultivated/ } \\
\text { managed vegetation }\end{array}$ & 6 & 46.9 \\
\hline Urban/ Built-up & 1.7 & 0 \\
\hline Barren & 0.7 & 1 \\
\hline
\end{tabular}
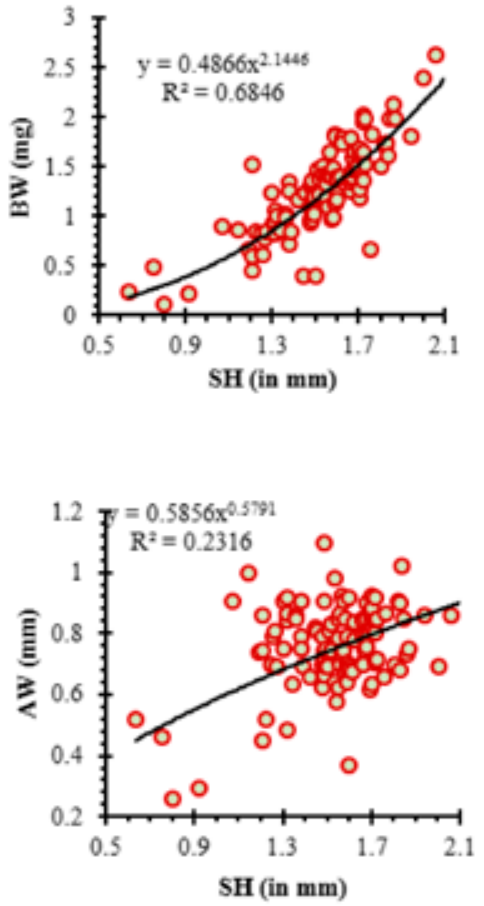
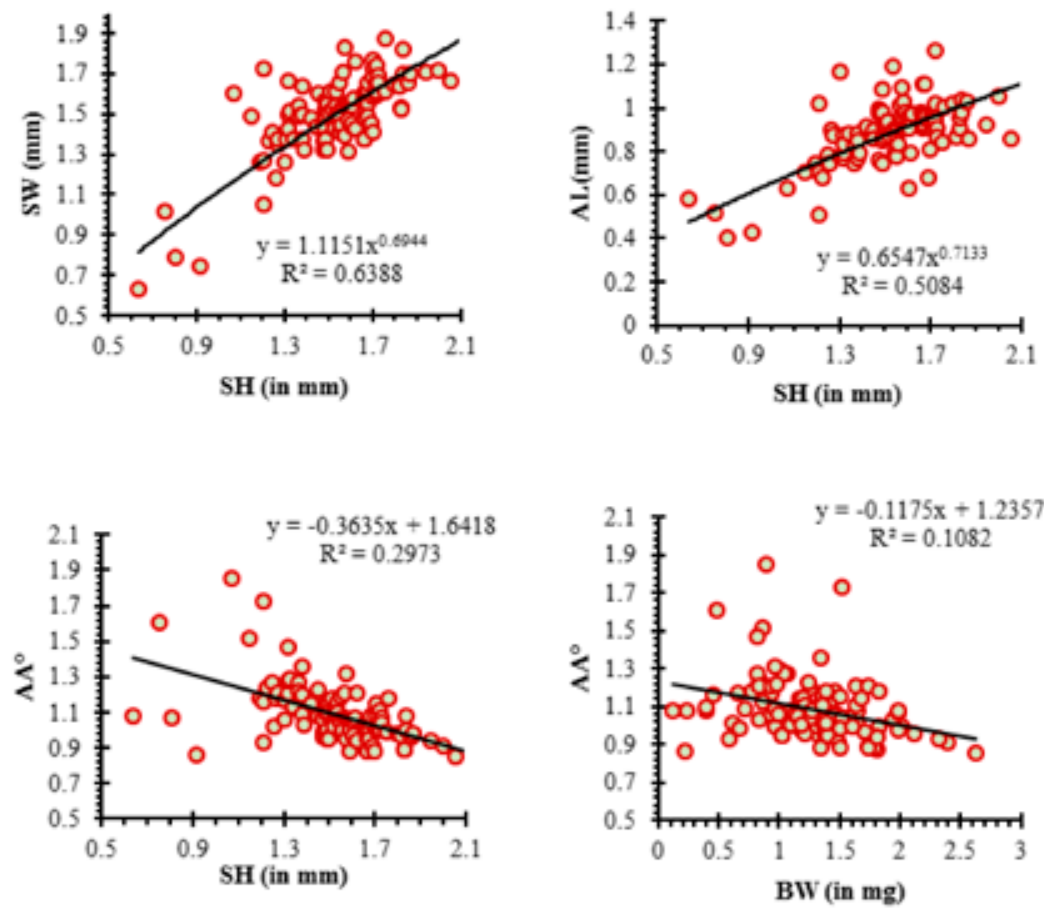

Figure 3. Relationship among the different variables defining the morphology and shell features of live P. dioscoricola $(\mathrm{n}=110)\left[\mathrm{AA}^{\circ}\right.$ - apical angle, $\mathrm{SH}$ - shell height in $\mathrm{mm}, \mathrm{SW}$ - shell width in $\mathrm{mm}, \mathrm{AL}$ - aperture length in mm, AW - aperture width in $\mathrm{mm}$, and $\mathrm{BW}$ - body weight in $\mathrm{mg}]$.

index was observed to be highest in case of $M$. indica, and lowest for C. nucifera (Figure 4b). Since the Jacobs' selectivity value of +1 denotes complete preference and the -1 value indicates complete rejection, it appears that $P$. dioscoricola preferred $M$. indica the most among the five host plants.

\section{Species distribution modelling}

The predicted distribution of the microsnail $P$. dioscoricola, based on the selected bioclimatic and land cover variables (Table 2a) is depicted in Figure 5. The Maxent model predicted that the discrete regions of the Himalayan Mountains and foothills, the Dooars region of northern West Bengal and a few parts of Paschim Bardhaman District, Kolkata and its adjacent areas have the highest probability of $P$. dioscoricola occurrence. The lowest probability of occurrence was predicted in a few discrete places of the Himalayan hills, western plateau and Sundarban reserve forest. A moderate to high probability of $P$. dioscoricola occurrence was predicted for the rest of the plains. The results of percent variable contribu- 
(a)

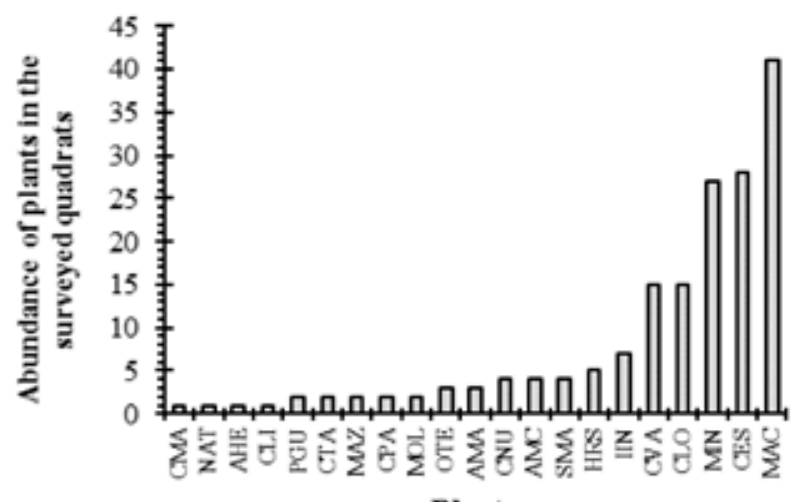

Plants (b)

\section{QMean abundance o Jacobs' selectivity}

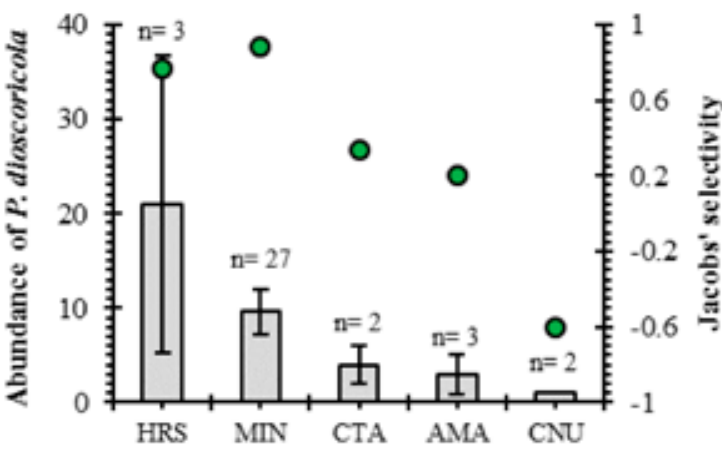

Host plant

Figure 4. (a) The number of different plants in the surveyed quadrats $(\mathrm{n}=16)$ where $P$. dioscoricola was encountered, which was further used in the plant preference analysis and (b) mean abundance ( \pm SE) of $P$. dioscoricola (' $n$ ' indicates the number of plants with the occurrence of $P$. dioscoricola) and Jacobs' selectivity (Jacob's selectivity value for the rest of the plants was -1 , hence excluded from the graph) for different host plants (Acronyms: CMA - Citrus maxima, NAT - Nyctanthes arbor-tristis, AHE - Artocarpus heterophyllus, CLI - Citrus limon, PGU - Psidium guajava, CTA - C. tabularis, MAZ - Melia azedarach, $\mathrm{CPA}$ - Carica papaya, MOL - Moringa oleifera, OTE - Ocimum tenuiflorum, AMA - A. marmelos, CNU - C. nucifera, AMC Alocasia macrorrhizos, SMA - Swietenia macrophylla, HRS - H. rosa-sinensis, IIN - Ipomoea indica, CVA - Codiaeum variegatum, CLO - Curcuma longa, MIN - Mangifera indica, CES - Colocasia esculenta, MAC - Musa acuminata).

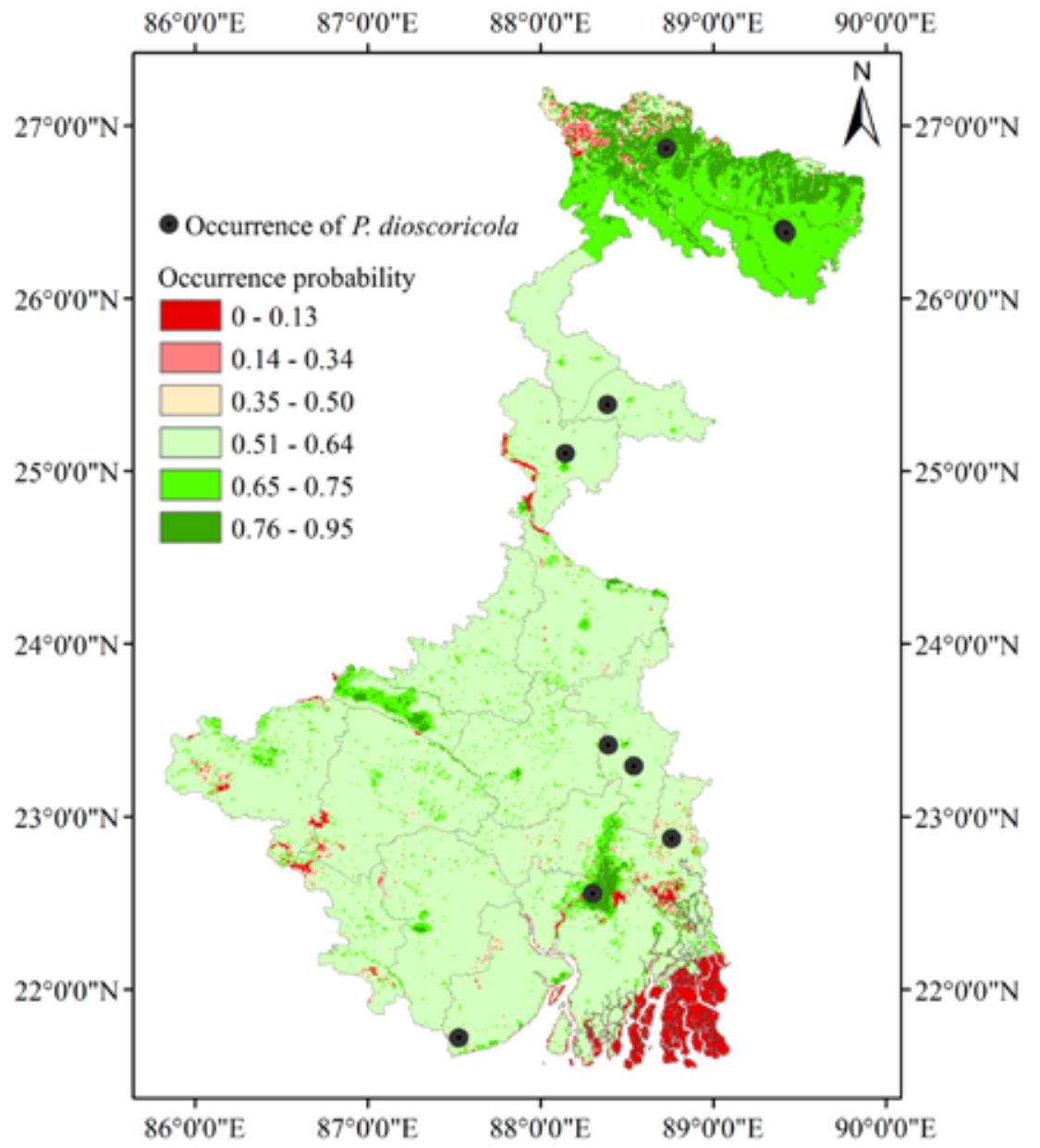

Figure 5. Predicted distribution of $P$. dioscoricola in West Bengal, India, based on Maxent species distribution modelling. The green regions represent areas with suitable habitats, while red regions represent areas less suitable for the microsnail P. dioscoricola. 
tion (Table $2 \mathrm{~b}$ ) and jackknife procedure suggested that, among the 14 bioclimatic and land cover variables, only 7 variables had a significant contribution to the model. Regularly flooded vegetation had the highest gain when used in isolation, therefore, appears to provide the most useful factor for the predicted $P$. dioscoricola distribution. Among the bioclimatic variables used in this model, annual precipitation had the highest contribution to the Maxent model. Based on the model, cultivated or managed vegetation and annual precipitation were the most influential variables for the distribution of $P$. dioscoricola (Table 2b). However, the $A U C$ value of this model was 0.720 , indicating its moderate performance based on the occurrence points and the environmental variables.

\section{DISCUSSION}

The shell morphology of the snail $P$. dioscoricola observed in the present study appears to comply with the observations made for specimens from the USA (Hausdorf 2007). In the present observation, the mean shell width was $1.5 \pm 0.02$ (mean $\pm \mathrm{SE}$ ) $\mathrm{mm}$ and the shell height was $1.53 \pm 0.02$ (mean $\pm \mathrm{SE}$ ) $\mathrm{mm}$, which is comparable to the mean shell height of $1.55 \mathrm{~mm}$ and shell diameter of $1.68 \mathrm{~mm}$ observed in the USA (Hausdorf 2007). The spire ratio of $P$. dioscoricola shell was 1.02 \pm 0.01 (mean $\pm \mathrm{SE}$ ), indicating a high spired mode like in other documented arboreal snail families such as Achatinillidae and Amastridae and supporting its arboreal mode of life (Cowie 1995). This value of the spire ratio was comparable to $P$. dioscoricola observed from the USA (1.09, Hausdorf 2007). Land snail habitat utilization and adaptability depends on its morphometric characteristics such as shell shape and size. The portrayal of the body size through the relationship between shell length and shell weight is observed in many terrestrial snails (Cain 1977; Cain and Cowie 1978; Cowie 1995; Preston and Roberts 2007). In this study, the shell height and body weight relationship of live $P$. dioscoricola $(\mathrm{n}=110)$ complied with the allometric equation (power regression was the best fit). Arboreal snails of family Achatinellidae and Pupillidae that can climb vertically, generally exhibit flat shape and bear a very large mouthed shell and high spired mode (h > d) (Cain 1977; Cain and Cowie 1978; Cowie 1995), different from discoidal, pointed and narrow shell shapes. With the increase in the shell height the spire ratio increased, while the apical angle decreased. Such relationships would mean that with increase in age, the shell changes from globular to the pointed form at the apical end which is also substantiated through the spire ratio. An increment in the spire ratio would mean the increase in height over the width of the shell. These observations show similarity with the observations on Calliostoma zizyphyinum (Preston and Roberts 2007), though studies using cohort-based individuals would provide a better picture of the variation in the shell shape in the course of ontogeny.

Empirical evidence suggests that the land snails utilize microhabitats such as rock crevices, litter, live trees, and deadwood due to high humidity and food resources. Among these varied habitat elements, rock crevices and deadwood were observed to be more preferred microhabitats (Sólymos et al. 2009; Kemencei et al. 2014). More specifically, the microsnails of the genus Pupisoma use various habitats, including aerial parts of trees, bird nests (Miquel et al. 2015), lichens and bryophytes (Pérez et al. 2008). In the USA, $P$. dioscoricola occurred in abandoned Citrus trees, on the undersides of leaves, leaf litter and carbonate rock outcrops (Nekola and Coles 2010). However, in the present study, $P$. dioscoricola was found on the leaves, stem and under the bark of the mentioned trees, but was not observed in Citrus trees and detritus. The selectivity of $P$. dioscoricola to its possible host plants may be due to the presence of microbiota, algae and fungi as a food source (Bledsoe and Minnick 1982), and grooves and crevices as sites for hiding from predators and for reproduction (Raut and Biswas 1991). In case of the microsnails, several factors like body size and biomass are considerably minuscule in dimension, which may limit their inclusion in the typical sample of the land snails. Therefore, suitable sampling methods (Sturm et al. 2006) are required for the collection and estimation of the relative abundance of microsnails as illustrated in several studies (Liew et al. 2008; Foon et al. 2017). Exploration of the detritus, soil and the allied terrestrial ecosystem elements provides an option to evaluate the distribution and the abundance of the land snails in the respective habitat (Sturm et al. 2006). However, in the present study, the time spent for the observations and sampling was increased for unit area within a quadrat along with visual scanning of the crevices created by the bark of the plants. The detritus and soil were also scanned thoroughly for the presence of living or shells of dead individuals.

As the microsnails are susceptible to anthropogenic disturbances such as deforestation and urbanization, and due to low dispersal ability, utilization of specialized habitats and small home ranges (Sen et al. 2012), conservation efforts should focus on population distribution and habitat preferences. As shown in this study, the abundance, plant preference patterns and predicted distribution range of $P$. dioscoricola may prove helpful in conservation. The observations on the distribution of the snails in the geographical area concerned also provide an impression about the possible spaces preferred. Exploration of the areas predicted by the model for a greater probability of encounter should be given priority for the habitat-based abundance and preference of $P$. dioscoricola. In recent times, priority 
areas for the conservation of the snails are highlighted in several studies that include forests (Fontaine et al. 2007; Ovando et al. 2019; Gheoca et al. 2021) as well as urban habitats (Barbato et al. 2017). On the basis of the prediction of the models, further assessment should be made to justify the status of $P$. dioscoricola as a dominant microsnail or not. Consequently, the determination of the conservation status can be made for the snail. In addition, the morphometric study of $P$. dioscoricola provides information about the prospective growth pattern in natural conditions. It is relevant to point out that the shell architecture of microsnails is highly diverse, as observed in China, Croatia, Japan and Malaysia (Kawakami et al. 2008; Weigand 2013; Cunha et al. 2015; Páll-Gergely et al. 2015; Vermeulen et al. 2015) as well as from India (Das and Aravind 2021). Although a few studies have highlighted the role of the microsnails in a community, the diversity, significance and population ecology of the microsnails at large are yet to be deciphered with greater details. In many instances, the shell characteristics (Liew and Schilthuizen 2014) and the habitat preferences provide key information on the population growth and trophic interactions (Panha and Burch 2005; Páll-Gergely et al. 2015) of the microsnails in the community. Considering the minuscule Pupisoma snail of India, studies encompassing trophic interactions, habitat preference and function roles should be initiated to address the issues related to population sustenance and conservation in nature. Nonetheless, the present information is a pioneer effort to highlight the habitat preferences and morphology of the snail $P$. dioscoricola, which may be helpful in the conservation management of the snail.

\section{ACKNOWLEDGEMENTS}

We thank Dr. Liew Thor Seng and two anonymous reviewers for providing critical remarks that improved the manuscript to its present form. The authors are grateful to the Head, Department of Zoology, University of Calcutta, Kolkata, West Bengal, India, for the facilities provided. PP acknowledges CSIR-HRDG, India [09/028(1115)/2019-EMR-1, dated 06/08/2019] for the financial support.

Funding Partial funding provided by CSIR-HRDG, Government of India [09/028(1115)/2019-EMR-1, dated 06/08/2019].

Conflicts of interest As authors of this article, we declare that we have no conflict of interest.

Authors' contributions HB and GA conceived the work; survey and collection executed by HB; photography and SEM study by PP; analysis and compilation GA, HB and PP.

\section{REFERENCES}

Addinsoft SARL. 2010. XLSTAT software ver.9.0. Addinsoft, Paris.

Aravind, N. A., K. P. Rajashekhar, and N. A. Madhayystha. 2005. Species diversity, endemism and distribution of land snails of the Western Ghats, India. Records of the Western Australian Museum Supplement 68: 31-38.

Aravind, N. A., R. K. Patil, and N. A. Madhyastha. 2008. Micromolluscs of the Western Ghats, India: Diversity, distribution and threats. Zoosymposia 1: 281-294.

Barbato, D., A. Benocci, T. Caruso, and G. Manganelli. 2017. The role of dispersal and local environment in urban land snail assemblages: an example of three cities in Central Italy. Urban Ecosystems 20: 919-931.

Barman, H., and G. Aditya. 2021. Does the micro land snail, Kaliella barrakporensis (Mollusca: Gastropoda), exhibit plant preference and aggregation? A spatial scale analysis. European Journal of Ecology 7 (1): 69-79.

Beltramino, A. A., R. E. Vogler, D. E. G. Gregoric, and A. Rumi. 2015. Impact of climate change on the distribution of a giant land snail from South America: predicting future trends for setting conservation priorities on native malacofauna. Climatic Change 131: 621-633.

Bledsoe, M. E., and D. R. Minnick. 1982. Citrus tree snail and suppression of Citrus microbiota. Environmental Entomology 11 (5): 1091-1095.

Cain, A. J. 1977. Variation in the spire index of some coiled gastropods shell, and its evolutionary significance. Philosophical Transaction of the Royal society of London, Series B 277: 377-428.

Cain, A. J., and R. H. Cowie. 1978. Activity of different species of land snails on surfaces of different inclinations. Journal of Conchology 29: 267-272.

Cowie, R. H. 1995. Variation in species diversity and shell shape in Hawaiian land snails: in situ species and ecological relationships. Evolution 49 (6): 1191-1202.

Cunha, C. M., R. B. Salvador, and L. R. L. Simone. 2015. The terrestrial microgastropods of Trindade Island, Brazil (Gastropoda, Pulmonata). Spixiana 38 (1): 139-143.

Das, N. K., and N. A. Aravind. 2021. A new species from the genus Georissa Blanford, 1864 (Gastropoda, Neritimorpha, Hydrocenidae) from a limestone cave of Meghalaya, Northeast India. Journal of Conchology 44 (2): 93-101.

Douglas, D. D., D. R. Brown, and N. Pederson. 2013. Land snail diversity can reflect degrees of anthropogenic disturbance. Ecosphere 4 (2): 28.

ESRI. 2019. ArcGIS v.10.8. ESRI, Redlands, California, USA.

Fick, S. E., and R. Hijmans. 2017. WorldClim 2: new 1km spatial resolution climate surfaces for global land areas. International Journal of Climatology 37 (12): 4302-4315. 
Fontaine, B., O. Gargominy, and E. Neubert. 2007. Land snail diversity of the savanna/forest mosaic in Lope National Park, Gabon. Malacologia 49 (2): 313-338.

Foon, J. K., G. R. Clements, and T. S. Liew. 2017. Diversity and biogeography of land snails (Mollusca, Gastropoda) in the limestone hills of Perak, Peninsular Malaysia. Zookeys 682:1-94.

Gheoca, V., A. M. Benedek, and E. Schneider. 2021. Exploring land snails' response to habitat characteristics and their potential as bioindicators of riparian forest quality. Ecological Indicators 132: 108289.

Hausdorf, B. 2007. Revision of the American Pupisoma species (Gastropoda: Pupilloidea). Journal of Natural History 41 (21): 1481-1511.

Hausdorf, B., M. Parr, L. J. Shappell, J. Oldeland, and D. G. Robinson. 2021. The introduction of the European Caucasotachea vindobonensis (Gastropoda: Helicidae) in North America, its origin and its potential range. Biological Invasions 23: 3281-3289.

Jacobs, J. 1974. Quantitative measurement of food selection. A modification of the forage ratio and Ivlev's electivity index. Oecologia 14: 413-417.

Kawakami, K., S. Wada, and S. Chiba. 2008. Possible dispersal of land snails by birds. Ornithological Science 7: 167-171.

Kemencei, Z., R. Farkas, B. Páll-Gergely, F. Vilisics, A. Nagy, E. Hornung, and P. Sólymos. 2014. Microhabitat associations of land snails in forested dolinas: implications for coarse filter conservation. Community Ecology 15 (2): 180-186.

Labaune, C., and F. Magnin. 2001. Land snail communities in Mediterranean upland grasslands: the relative importance of four set of environmental and spatial variables. Journal of Molluscan Studies 67: 463-474.

Liew, T., and M. Schilthuizen. 2014. Association between shell morphology of micro-land snails (genus Plectostoma) and their predator's predatory behaviour. PeerJ 2: e329.

Liew, T. S., R. Clements, and M. S. Thuizen. 2008. Sampling micromolluscs in tropical forests: one size does not fit all. Zoosymposia 1: 271-280.

Madhyastha, N. A., and K. D. Mumbrekar. 2016. The land snail of Sharavathi river basin, Karnataka, India. http:// www.ces.iisc.ernet.in/biodiversity/sahyadri_enews/ newsletter/issue20 /article3.html

Miquel, S. E., P. Turienzo, and O. R. Di Iorio. 2015. Gastropod species found in birds' nests from Argentina. Revista del Museo Argentino de Ciencias Naturales 17: 87-96.

Mitra, S. C., A. Dey, and Ramakrishna.2005. Pictorial Handbook - Indian Land Snails (Selected Species). Kolkata, India.

Nekola, J. C., and B. F. Coles. 2010. Pupillid land snails of eastern North America. American Malacological Bulletin 28: 29-57.

Ovando, X. M. C., M. J. Miranda, R. Loyola, and M. G. Cue- zzo. 2019. Identifying priority areas for invertebrate conservation using land snails as models. Journal for Nature Conservation 50: 125707.

Páll-Gergely, B., A. Hunyadi, A. Jochum, and T. Asami. 2015. Seven new hypselostomatid species from China, including some of the world's smallest land snails (Gastropoda, Pulmonata, Orthurethra). ZooKeys 523: 31-64.

Panha, S., and J.B.Burch. 2005. An introduction to the microsnails of Thailand. Malacological Review 37-38: $1-155$.

Pérez, A., M. M. Sotelo, I. Arana, and A. López. 2008. Diversidad de moluscos gasterópodos terrestres en la region del Pacífico de Nicaragua y sus preferencias de hábitat. Revista de Biología Tropical 56: 317-332.

Peterson, A. T., J. Soberón, R. G. Pearson, R. P. Anderson, E. Martínez-Meyer, and M. Nakamura. 2011. Ecological Niches and Geographic Distributions. Princeton, New Jersey: Princeton University Press.

Phillips, S. J. 2017. A Brief Tutorial on Maxent. Available from url: http://biodiversityinformatics.amnh.org/ open_source/maxent/. Accessed on 2021-9-19.

Phillips, S. J., R. P. Anderson, and R. E. Schapire. 2006. Maximum entropy modelling of species geographic distributions. Ecological Modelling 190 (3-4): 231-259.

Pilsbry, H. A. 1920-1921. Manual of Conchology, second series: Pulmonata. Vol. 26. Pupillidae (Vertigininae, Pupillinae). Academy of Natural Sciences of Philadelphia.

Preston, S. J., and D. Roberts. 2007. Variation in shell morphology of Calliostoma zizyphinum (Gastropoda: Trochidae). Journal of Molluscan Studies 73 (1): 101-104.

Raheem, D. C., H. Taylor, J. Ablett, R. C. Preece, N. A. Aravind, and F. Naggs. 2014. A Systematic Revision of the land snails of the Western Ghats of India. Tropical Natural History 4: 1-294.

Rao, H. S. 1925. On certain succineid molluscs from the Western Ghats, Bombay Presidency. Records of the Indian Museum 27: 385-400.

Raut, S. K., and K. C. Ghose. 1984. Pestiferous land snails of India. Zoological Survey of India 11: 1-151. Calcutta, Bani Press.

Raut, S. K., and A. Biswas. 1991. Natural History of the tree snail Rhachis bengalensis Lamarck (Gastropoda: Enidae). Bulletin of Malacology, R.O.C. 16: 75-80.

Salvador, R. B., D. C. Cavallari, and L. R. L. Simone. 2017. Taxonomical study on a sample of land and freshwater snails from caves of Central Brazil, with description of a new species. Zoosystematics and Evolution 93 (1): 135-141.

Sen, S., G. Ravikanth, and N. A. Aravind. 2012. Land snails (Mollusca: Gastropda) of India: status, threats and conservation strategies. Journal of Threatened Taxa 4 (11): 3029-3037.

Sólymos, P., R. Farkas, Z. Kemencei, B. Páll-Gergely, 
F. Vilisics, A. Nagy, M. Kisfali, and E. Hornung. 2009. Micro-habitat scale survey of land snails in dolines of the Alsó-hegy, Aggtelek National Park, Hungary. Mollusca 27 (2): 169-173.

Sow-Yan, C., and L. W. Lup. 2020. New Singapore record of toothless pupa snail, Pupisoma dioscoricola. Singapore Biodiversity Records 2020: 156-158.

Sturm, C. F., T. A. Pearce, and A. Valdés. 2006. The Mollusks: a guide to their study, collection, and preservation. Florida: Universal Publishers.

Tongkerd, P., C. Sutcharit, and S. Panha. 2013. Two new species of micro land snails from two islands Andaman sea (Prosobranchia: Diplommatinidae; Pulmonata: $\mathrm{Pu}-$ pillidae). Tropical Natural History 13 (2): 65-76.

Tuanmu, M. N., and W. Jetz. 2014. A global 1-km consensus land-cover product for biodiversity and ecosystem modelling. Global Ecology and Biogeography 23 (9): 1031-1045.
Vermeulen, J. J., and J. G. M. Raven. 1998. A note on the genera Costigo and Pupisoma (Gastropoda, Pulmonata: Vertiginidae). Basteria 62: 273-275.

Vermeulen, J. J., T-S. Liew, and M. Schilthuizen. 2015. Additions to the knowledge of the land snails of Sabah (Malaysia, Borneo), including 48 new species. Zookeys 531: 1-139.

Vogler, R. E., A. A. Beltramino, M. M. Sede, D. E. G. Gregoric, V. Núñez, and A. Rumi. 2013. The giant African snail, Achatina fulica (Gastropoda: Achatinidae): Using bioclimatic models to identify South American areas susceptible to invasion. American Malacological Bulletin 31 (1): 39-50.

Weigand, A. M. 2013. New Zospeum species (Gastropoda, Ellobioidea, Carychiidae) from $980 \mathrm{~m}$ depth in the Lukina Jama-Trojama cave system (Velebit Mts., Croatia). Subterranean Biology 11: 45-53.

Zar, J. H. 1999. Biostatistical Analysis. IV ed. New Delhi, India: Pearson Education Singapore Pte. Ltd, Indian Branch. 